Psychology of Language and Communication 2012, Vol. 16, No. 3

VERSITAOPEN

DOI: $10.2478 / \mathrm{v} 10057-012-0013-9$

\author{
SANDRINE GAYMARD \\ University of Angers
}

\title{
PEDESTRIAN REPRESENTATION THROUGH THE ANALYSIS OF LITTLE STORIES
}

\begin{abstract}
This research is concerned with the problem of pedestrians as vulnerable road users. It falls within the study of social representations and risk. In this study, the representation of pedestrians by both young and experienced drivers was analyzed. A questionnaire of eleven little stories was devised and used to contextualize the environment more clearly. The participants had to make up an ending for the story according to their own behavior or feelings in each situation. Multiple correspondence analysis via the categorization of the verbatim accounts reveals homogeneity in the reactions and feelings of both groups. This homogeneity reflects the importance of civil attitudes in situations of interaction since they call on the notion of "respect." Finally, the qualitative approach of the little stories highlights the place of emotions in specific driver-pedestrian interaction contexts.

Key words: social representations, risk, the questionnaire of little stories, young drivers, experienced drivers, pedestrians, feelings
\end{abstract}

\section{Introduction}

The notion of social representation first appeared in Moscovici's work on the image of psychoanalysis in France (1961/76). In this work he shows how a new theory spreads in a given culture, how it is transformed in the process and how in turn it changes the view that people have of themselves and the world in which they live (Farr, 1984). In this work Moscovici reveals two essential processes: objectification and anchoring. The former allows a concept to be transformed into an image, into a figurative core, and the latter explains how new knowledge is integrated into a set of more familiar knowledge. For Moscovici"social representation is a particular modality of knowledge whose function is the elaboration of behavior and com-

Address for correspondence: Sandrine Gaymard, LUNAM Université, University of Angers, Laboratoire de Psychologie des Pays de la Loire (LPPL), UPRES EA 4638, Maison des Sciences Humaines, 5 bis boulevard Lavoisier, 49045 Angers cedex 01, France. E-mail: sandrine.gaymard@univ-angers.fr 
munication between people" (trans., from French, 1976, p. 26). The notion of social representation is inspired by Durkheim's concept of "collective representation" (1898/1967), but Moscovici considers the former to be better adapted to new societies which are characterized by change and diversity. According to Moscovici, the representational process always develops within a situation of social interaction, giving rise to shared knowledge also called "commonsense knowledge." This form of knowledge is an integral part of the groups that develop it and is distinct from scientific thought in that it is natural and spontaneous. Representations allow individuals to give a meaning to their behavior and to understand the environment according to their own system of reference. Moscovici sees a double vocation in the notion of representation: a function of adaptation to the environment, largely defended by Piaget (1977), and a social function. All these considerations confirm the relevance of the Social Representation Theory (SRT) which covers four main functions: knowledge, group identity, behavior orientation and justification (Abric, 1994). Representations are fundamental to understanding the relations between individuals and society (Jovchelovitch, 1996) and are directed toward exploring the explanations that arise from new events (Hewstone \& Augoustinos, 1998).

Moscovici's first works gave rise to several directions of research and to a large quantity of literature on social representations (Farr, 1987; Wagner, 1996). Abric (1976) proposed the structural approach; he argues that social representations are organized around a central core defined as consensual and absolute with a fluctuating conditional periphery linked to individual practices. Social representation is a socio-cognitive system presenting a specific organization whose methodological consequence requires the core and peripheral elements to be sought. In this framework there exist a number of methods and tools to analyze and understand thought and social practices (Abric, 2003; Gaymard, 2003; Tsoukalas, 2006). For example, Gaymard (2003) uses a multi-methodological approach in order to study the problems of intercultural negotiation among young Franco-Maghrebian women. Alongside quantitative tools, the author develops a technique called "little stories" that consists in elaborating little scenarios to be completed. This method leads interviewees to project themselves beyond spontaneous discourse and makes it possible to investigate certain themes that require a more qualitative approach. Thus, the author's results show the advantage of this method in shedding light on the problems of women confronted with marriage and the underlying conflicts with their parents.

Another approach is that of the theory of "organizing principles" advocated by Doise (1985). This stresses the organization of inter-individual differences in the representational domain. Representations are thus defined as "....generating principles of stand taking linked to specific insertions...” (trans., from French, p. 245). From a methodology point of view this current has widely defended factorial analysis methods which empirically highlight different social representation dynamics (Doise, Clemence, \& Lorenzi-Cioldi, 1992). 


\section{Social Representation Theory (SRT) in the field of risk and hazard}

The English-language literature on the Social Representation Theory (SRT) in the field of risk and hazard (Bauer \& Gaskell, 1999; Breakwell, 2001, 2007; Joffe, 1999, 2003; Joffe \& Lee, 2004) contributes to the questions posed by the insertion of affective elements into representation, defined as fundamental from the beginning (Moscovici, 1961/1976).

In the field of risk perception, judgment and decision-making in the face of risk, a strong cognitive method centered on individual processes and cognitive bias has predominated since the 1950s (Tversky \& Kahneman, 1974). As Joffe (2003) emphasizes, a new shift toward recognizing the importance of emotions has emerged from the 1990s. Historically, Zajonc (1980) was an early defender of the importance of affect in decision-making. Finucane, Alhakami, Slovic, and Johnson (2000) show that individuals judge the risk and the benefit it involves via positive and negative feelings which they associate with it, so they use an "affect heuristic." Alhakami and Slovic (1994) have shown that the relation between perceived risk and the benefit from the risk are linked to a personal and affective assessment of the risk. When the activity is appreciated, the risk is judged to be low and the benefit high. In the reverse case, when the activity is not appreciated, the judgments are the opposite.

Starting from empirical works on the representation of risks linked to biotechnologies and health, Joffe (2003) juxtaposes the point of view of perception models with the approach of social representations. Perception models focus on intra-personal processes, often excluding wider influences, and rely on deficient risk conceptualization. The social representations approach replaces this model of static risk perception with a dynamic model. The response to risk constitutes a social, emotional and symbolical entity, as representations can protect from the anxiety created by a hazard (considered to be a consequence of risk, Breakwell, 2007). To study the images produced by the 2001 Hong Kong avian flu epidemic, Joffe and Lee (2004) used the social representation theory. They showed that representation was structured around explanations of the origins of the epidemic and emotions. Following Breakwell (2007), the SRT of hazards could explain the functioning of the principles of intensification and attenuation: "It suggests that the subcultural base for any individual's representation of a hazard will influence their susceptibility to any reframing attempts, including official interventions aimed at changing risk perceptions" (p. 257).

\section{The perception of risk in relation to age and driving experience}

In the field of road safety, several studies have been concerned with the perception of risk in relation to age and driving experience; a certain number of these studies are based on oculometric data. Underwood, Phelps, Wright, Loon, and Galpin (2005) compared the eye fixation scanpaths of younger (30-45 years) and older drivers (60-75 years) in a hazard perception task. They show that the detec- 
tion of hazards was similar for older and younger drivers although the films were perceived as being more hazardous in general by older drivers. In a recent study, Borowsky, Shinar, and Oron-Gilad (2010) examined the effects of age and driving experience on the capacity to detect risks while driving. They compared groups of young, experienced and elderly drivers who viewed six films on hazard perception while their eye movements were recorded with eye tracking. The results show that experienced and more-elderly-experienced drivers are equally competent in detecting a hazard and they continually detect potentially hazardous events (e.g. with pedestrians), which is not the case of young-inexperienced drivers. Measurement of eye movements reveals that all the drivers detect elements of the environment when they are salient but looking right at an intersection only characterizes experienced drivers. The study shows that experienced drivers are more capable of perceiving and recognizing potential hazards. Using a framework of "novice drivers' competencies," Evans and Macdonald (2002) analyze, in an exploratory study, awareness and hazard perception in novice drivers. They have recorded oral commentaries about the driving task, traffic situation and road environment and observe interesting differences between day and night commentaries. They suggest that the higher perceptual salience of some objects at night could focus the drivers' attention, thus reducing their global performance.

These results confirm the previous work of Finn and Bragg (1986), who show that young drivers considered their own risk of being involved in an accident less likely than that of both their peers and older male drivers. This lends support to the idea that young male drivers fail to perceive certain risky situations as older drivers perceive them.

By studying the judgments of young drivers and experienced ones faced with traffic scenes, Groeger and Chapman (1996) show that drivers assess situations by using highly consistent dimensions via a vast range of traffic situations. Younger drivers concentrate on the danger rather than on the difficulties involved in executing particular maneuvers and so underestimate the dangers with which they are confronted.

Crundall, Underwood, and Chapman (1999) looked into the relations between the behavior of eye scanning, available attentional resources and the perception of traffic situations in young drivers. They showed that experienced drivers need to concentrate their attention less because of a more automatic development level of competence. Maycock and Forsyth (1997) demonstrated that mistakes in awareness and anticipation on the part of young drivers were the best accident predictors in both girls and boys. Among these mistakes one can find incorrect anticipation of the action of cyclists, crossing pedestrians or other drivers.

\section{Drivers' perception of pedestrians}

Studies dealing more specifically with drivers' perception of pedestrians remain limited. For instance, Sarkar and Andreas (2004) highlighted a lack of awareness of pedestrians' legal rights; they used photos to evaluate drivers' level of sensitivity 
and noted a certain insensitivity in situations of conflict between drivers and pedestrians suggesting that "....aggressive acts toward pedestrians need to be included in the definition of aggressive driving so that drivers are made aware of the rights of pedestrians" (p. 75). In order to study drivers' perception of pedestrians, Gaymard, Boucher, Nzobounsana, Greffier, and Fournela (2012) associate visual saliency measures taken from recordings of road scenes with data from the discourse transcript of drivers viewing these same scenes. The link between the measures of saliency and the elements noticed by the drivers is shown in the findings. A pedestrian can be seen to stand out when the driver is not in a crowded environment and if they interact in a pedestrian zone or in a courteous manner. These results demonstrate that drivers' perception of pedestrians depends on environmental characteristics linked to a feeling of security versus insecurity. Drivers were particularly sensitive to the pedestrian's attitude. A "provocative" pedestrian (who knowingly defies the driver) arouses aggressiveness in drivers and a courteous pedestrian produces positive feelings (Gaymard, Boucher, Nzobounsana, Greffier, and Fournela, 2012). Finally, in a driving context with interactions between drivers and pedestrians, identifying the pedestrian's attitudes as being respectful or not determines the expression of positive or negative feelings in drivers.

Other studies show the place of culture in representation (Andrés \& Gaymard, 2010; Gaymard, Andrés \& Nzobounsana, 2011). For example, Gaymard, Andrés \& Nzobounsana (2011) used the method of little stories to compare the reactions and feelings of young French and Spanish drivers when interacting with pedestrians. With this method, the authors show great homogeneity in the answers.

With the literature in mind and considering the above observations, the aim of this study is to find out how young drivers and experienced ones view pedestrians, using a method in which the subjects are given little stories to complete.

\section{Method}

\section{Participants}

The study population consisted of 20 young drivers and 20 experienced drivers. The young drivers included 14 women and 6 men, their average age being 20.8 years $(S D=1.51)$. The majority were students who had, on average, had their driver's license for 21 months.

The experienced drivers included 9 women and 11 men, their average age was 44.75 years $(S D=4.37)$ and the majority were office workers who had, on average, had their driver's license for 26 years.

\section{Material}

From exploratory interviews enabling the dimensions of the representation to be determined, we formulated a little story questionnaire. 
Eleven little stories (see Appendix) were created using the model of Gaymard (2003). The participants had to make up an ending for the story according to their own behavior or feelings in this precise situation. In the instructions, they were informed they should answer as a driver in all the situations. Each time, they were asked to interact in a specific environment: town/country; daytime/nighttime; number and type of road users (pedestrian alone or in a group, cyclist), framework (sidewalk, road, lights...), in relation to the characteristics (elderly pedestrian, pedestrian with a burden), behavior and attitudes of the pedestrians (impatient, courteous, disrespectful, provoking pedestrian). The elaboration of these stories was based on intuitive hypotheses. For example, in the case of story number 1 (see Box 1), the principle is to associate the pedestrians' reprehensible behavior with a friendly gesture on their part. In the exploratory interviews, the subjects had referred to bad pedestrian behavior and lack of courtesy. In the elaboration of this story, we thought a pedestrian showing courtesy would be appreciated more.

Box 1: Little story No. 1

"While you are driving in town, a pedestrian steps out inconsiderately. You let him or her cross and receive a sign of thanks......."

\section{Data analysis}

The subjects' answers were categorized according to the behavior and/or feelings generated by the story's context. We obtained 11 categories: "Aggressiveness," "Conditional," "Insensitivity," "Pedestrian priority," "Pedestrian priority aggressiveness," "Pedestrian priority remark," "Pedestrian priority negative feeling," "Negative feeling," "Positive feeling," "Attention," "Remark." Subsequently, we used multiple correspondence analysis (Benzecri, 1980), which is an extension of simple correspondence analysis to more than two variables. This method is employed to analyze a set of observations coming from a set of nominal or categorical variables. It is referred to by several authors in the field of social representations (Doise, Clemence \& Lorenzi-Cioldi, 1992; Languin, Widmer, Kellerhals \& Robert, 2004; RolandLévy, 2004; Viaud, 2005; Widmer, Languin, Pattaroni, Kellerhals \& Robert, 2004). For example, Doise et al. (1992) illustrated how factorial correspondence analysis allowed the concept of fields of representation to be formalized.

\section{Results}

Concerning the little stories and the participants' characteristics, we found only two significant differences. The first was between the sexes in story 7 (see Appendix): $\chi^{2}(8, N=40)=12,246, p<0.15$, Cramér's $V=0.55$, and the second was between types of experience (young driver vs. experienced driver) in story 4 : $\chi^{2}(2, N=40)=4,444, p<0.15$, Cramér's $V=0.33$. In both cases the men and young drivers seem less charitable when interacting with pedestrians. 
Table 1. Multiple correspondence analysis, categories and coordinates

\begin{tabular}{lccccc}
\hline Categories & \multicolumn{5}{c}{ Coordinate } \\
\hline Attribute = value & Coord 1 & Coord 2 & Coord 3 & Coord 4 & Coord 5 \\
Sex = male & -0.13 & -0.08 & 0.08 & -0.31 & 0.38 \\
Sex = female & 0.1 & 0.07 & 0.07 & 0.25 & -0.31 \\
Experienced drivers & -0.06 & -0.03 & 0.04 & -0.13 & 0.34 \\
Young drivers & 0.05 & 0.03 & -0.04 & 0.13 & -0.33 \\
Aggressiveness & 0.67 & -0.48 & 1.22 & -0.31 & 0.03 \\
Conditional & 0.25 & -0.46 & -1.09 & -0.9 & 0.98 \\
Insensitivity & -0.16 & 0.09 & -0.94 & -1.29 & -1.6 \\
Pedestrian priority & 0.36 & -0.43 & -0.96 & 0.53 & 0.47 \\
Pedestrian priority aggressiveness & 0.58 & -0.43 & -0.31 & 2.78 & 0.58 \\
Pedestrian priority remark & 0.56 & -0.29 & -0.49 & 1.73 & -2.88 \\
Pedestrian priority negative feeling & 0.63 & -0.38 & -0.09 & 1.91 & -1.79 \\
Negative feeling & 0.73 & 1.53 & 0.14 & 0.68 & -0.61 \\
Positive feeling & 0.83 & 3.59 & 0.07 & -0.14 & 0.69 \\
Attention & -1.95 & 0.15 & 0.37 & 0.24 & 0.11 \\
Remark & 0.62 & -0.45 & -0.06 & 2.62 & -0.7 \\
Courteous pedestrian (story 1) & 0.78 & 3.11 & 0.15 & -0.18 & 0.24 \\
Elderly pedestrian (story 11) & 0.57 & -0.3 & -0.25 & 1.72 & 0.3 \\
Pedestrian green light (stories 2 \& 7) & 0.54 & -0.38 & 0.07 & 0.53 & -0.56 \\
Pedestrian with a burden (story 6) & 0.1 & -0.35 & -1.33 & -0.44 & 0.83 \\
Disrespectful pedestrian (story 4) & 0.72 & -0.62 & 1.73 & -0.92 & 0.19 \\
Pedestrian sidewalk (stories 3 \& 5) & -0.05 & -0.12 & -0.88 & -1.29 & -1.88 \\
Provoking pedestrian (story 9) & 0.65 & -0.47 & 0.93 & -0.15 & 0.34 \\
Country pedestrian (stories 8 \& 10) & -2 & 0.18 & 0.42 & 0.24 & -0.02 \\
\hline
\end{tabular}

In order to study the link between the type of story and the discourse of those questioned, we used multiple correspondence analysis (MCA; see Table 1 and Table 2).

The first factorial plane (formed by the first two factorial axes; Figure 1) shows the existence of three groups, of which the first two are clearly identified in this plane: on one hand, stories in a rural context which are associated with the driver's attentiveness (story in which the pedestrian is not very perceptible) and on the other hand, the story in an urban context in which the courteous pedestrian generates more positive than negative feelings in the driver questioned. 
Table 2. Eigen values

\begin{tabular}{cccc}
\hline Axis & Eigen Value & \% Explained & \% Cumulated \\
\hline 1 & 0.476266 & $10.03 \%$ & $10.03 \%$ \\
2 & 0.443076 & $9.33 \%$ & $19.35 \%$ \\
3 & 0.408366 & $8.60 \%$ & $27.95 \%$ \\
4 & 0.340299 & $7.16 \%$ & $35.12 \%$ \\
5 & 0.33543 & $7.06 \%$ & $42.18 \%$ \\
6 & 0.296784 & $6.25 \%$ & $48.43 \%$ \\
7 & 0.287107 & $6.04 \%$ & $54.47 \%$ \\
8 & 0.266334 & $5.61 \%$ & $60.08 \%$ \\
9 & 0.258505 & $5.44 \%$ & $65.52 \%$ \\
10 & 0.25 & $5.26 \%$ & $70.78 \%$ \\
11 & 0.247814 & $5.22 \%$ & $76.00 \%$ \\
12 & 0.233928 & $4.92 \%$ & $80.92 \%$ \\
13 & 0.218878 & $4.61 \%$ & $85.53 \%$ \\
14 & 0.186816 & $3.96 \%$ & $89.47 \%$ \\
15 & 0.171139 & $3.60 \%$ & $93.07 \%$ \\
16 & 0.155074 & $3.26 \%$ & $96.33 \%$ \\
17 & 0.091711 & $1.93 \%$ & $98.26 \%$ \\
18 & 0.057316 & $1.21 \%$ & $99.47 \%$ \\
19 & 0.025157 & $0.53 \%$ & $100.00 \%$ \\
\hline
\end{tabular}

Figure 1. Little stories: First factorial plane

Multiple Correspondence Analysis (MCA)

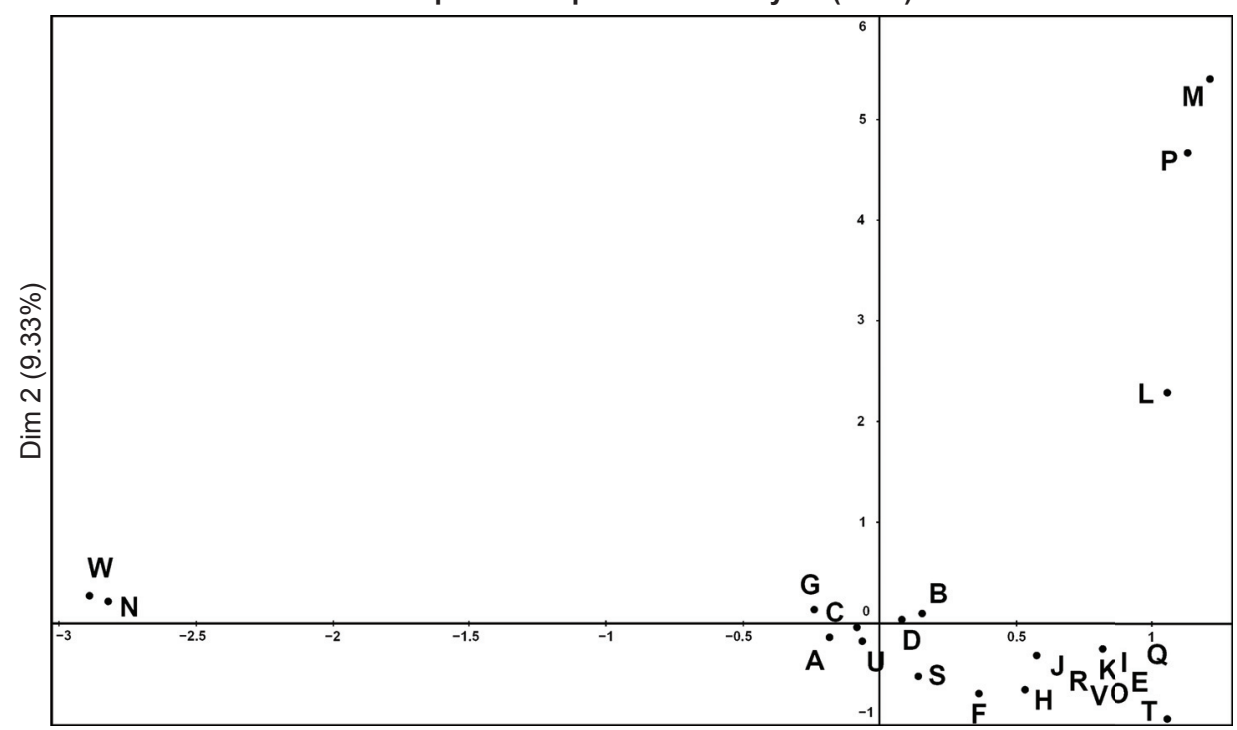


Figure 2. Little stories: Second factorial plane

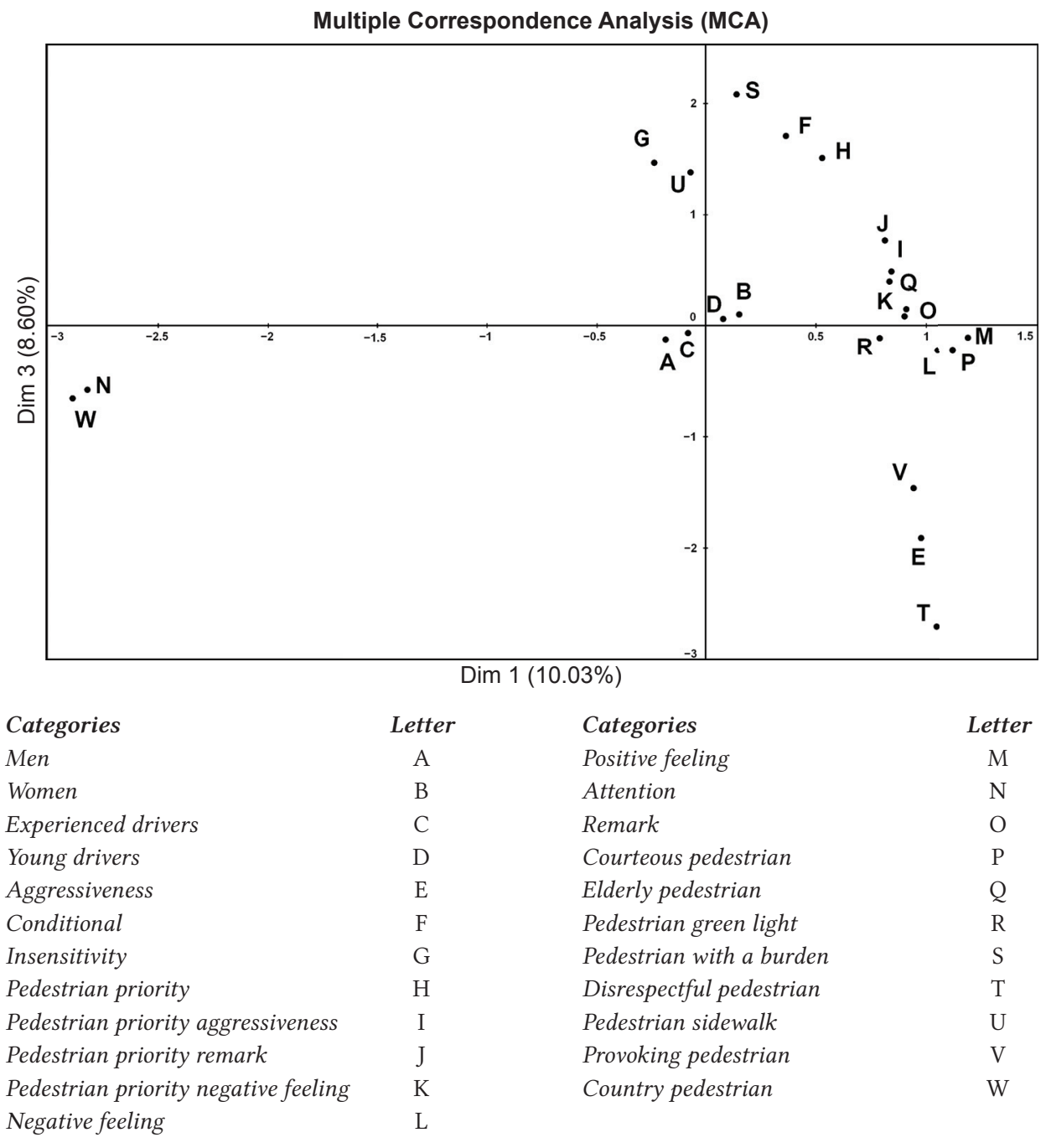

The second factorial plane (Figure 2) reveals the third group which splits into three sub-groups, each in an urban context:

- For one group, the aggressive reactions of the driver questioned are associated with the stories "provoking pedestrian" and "disrespectful pedestrian".

- For the second group, the insensitivity of the driver questioned (the driver continues on his way) or the priority given to the pedestrian are associated with the pedestrian on the sidewalk or the pedestrian with a burden. 
- For the third group, annoyance and priority given unwillingly are associated with pedestrians who step out when the light is green for the driver or with the story about an elderly pedestrian.

\section{Discussion}

This research into pedestrian representation deals more globally with a problem of society, i.e. the management of road user interactions in a context of change. Today it proves necessary to reduce the negative impact of road traffic on city-dwellers' lives and to promote energy saving, notably the use of more environment-friendly means of transport. Alongside the use of public transport, ecomobility and using means of transport called "doux" (gentle) are more and more common. These means of transport include the bicycle, walking and other non-polluting alternatives of this kind. Moreover, the multiplication of these means of transport highlights the problem of vulnerable road users which has led to the introduction of the "principe de prudence" (principle of caution) toward them in the Highway Code of July 2008 ("The principle of caution of the user toward the most vulnerable" Act of 2008-754, July 30,2008 ). The pedestrian is particularly exposed in the field of accidentology and has been the subject of studies using different approaches (Gaymard, Andrés, \& Nzobounsana, 2011; Gaymard, Boucher, Nzobounsana, Greffier, \& Fournela, 2012; Holland \& Hill, 2007; Khan, Jawaid, Chotoni, \& Luby, 1999; Krotosky \& Trivedi, 2007; Maeda et al., 2009; Schmidt \& Färber, 2009; Thompson, Fraser \& Howarth, 1985). However, as Tom, Auberlet, and Brémond (2008) point out, pedestrian-vehicle interactions are not analyzed by most of the simulation models even though these interactions are crucial.

The method of little stories (Gaymard, 2003; Gaymard, Andrés \& Nzobounsana, 2011) is a qualitative approach which makes it possible to analyze people's discourse in contextualized environments. The other advantage to this method is that it reveals the emotional component of the representations.

Thus hypotheses can be tested by orienting the discourse toward specific real-life situations. Gaymard (2003) proposed this approach in a study which dealt with problems of biculturalism among young women of Maghrebian origin. For example, the author tested the importance of parents' trust in these circumstances. By constructing a specific story concerning a young woman of Maghrebian origin, Gaymard showed that a large majority of the answers reflected the importance of this parental trust.

Concerning the problems of driver-pedestrian interactions, our results confirm that two variables seem important in these interactions: the perception of respecting or not respecting the Highway Code and the attitudes of the pedestrian (Gaymard, Agbotsoka \& Nzobounsana, 2009; Gaymard, Boucher, Nzobounsana, Greffier, \& Fournela, 2012). An example of the perception of disrespectful pedestrians involves not using pedestrian crossings. For the driver, a pedestrian who crosses outside 
the pedestrian crossing is "illegitimate." This perceived non-legitimacy creates bad feelings because drivers feel a lack of respect on the part of pedestrians toward drivers and express this feeling. However, studies show that, for themselves, the drivers appear very conditional concerning the Highway Code (Gaymard, 2007, 2009; Gaymard, Allain, Osiurak, \& Le Gall, 2011).

On one level in this study, we note some differences with regard to sociodemographic variables. Story 7 , which describes a group of pedestrians stepping out on a green light (for the drivers), distinguishes between women and men. Likewise, story 4, which describes a pedestrian steping out inconsiderately without looking at the driver, distinguishes between young drivers and experienced ones. In both stories, the men and young drivers seem less understanding toward the pedestrians. But despite these differences, the results prove a strong consistency in the reactions of the drivers with earlier results comparing French and Spanish drivers (Gaymard, Andrés, \& Nzobounsana, 2011).

All the accidentology data point to an over-representation of young male drivers. Studies show that young drivers have difficulty in identifying hazards (Pollatsek, Fischer, \& Pradhan, 2006; Scialfa et al., 2011) and that driving experience increases anticipation (Chan, Pradhan, Pollatsek, Knodler, \& Fisher, 2010; Garay-Vega, Fisher, \& Pollatsek, 2007; Groeger \& Chapman, 1996). However, when studying the reactions to attitudes of civility and incivility, these reactions seem to be shared by all drivers.

Factorial analysis reveals a first plane whose distinctive feature is that it isolates the only context in which the description of the pedestrian gives rise to a greater number of careful reactions or positive feelings than reactions of conflict. This first plane notably isolates the only story that shows a sign of courtesy from the pedestrian (story 1), which confirms the importance of small gestures likely to maintain a climate of serenity between road users in a situation of interaction. In this story, in which the pedestrian intrudes at first, the sign of thanks that follows reduces the driver's aggressiveness. Courtesy is important to the driver who gives way to the pedestrian. The notion of "citoyenneté" (social civility) in the perspective of "territorial sharing" is crucial and implies values concerning respect for others. In France, however, it must be noted that since the Highway Code changed (Act No. 2010-1390, November 12, 2010) the pedestrian is considered to have priority everywhere; "...as soon as he steps out or clearly shows his intention to step out on to the road, the driver shall give way" (article 17). This new act could be thought to have an impact on representations in the long term. "Road sharing" also implies courtesy and even if they are within their rights, pedestrians can maintain a climate of serenity between road users by giving signs of thanks and smiling. In this first plane, the only story which generates more positive than negative feelings is opposed to the rural context. This specific context gives rise to careful reactions, as meeting pedestrians on the side of the road is more unexpected. 
The second factorial plane underlines the climate of conflict between road users but the notion of giving way to the pedestrian prevails in the discourse. Drivers thus show that even if they disagree or are annoyed by pedestrians, they are aware of their vulnerability. On this second plane a continuum can be observed between the insensitivity of the driver and the aggressiveness he expresses experiencing priority given unwillingly. The content of the little stories conveys a spontaneous discourse bearing little relation to social desirability, as the importance of the drivers' negative reactions shows. Nevertheless the aggressiveness described between drivers on the road appears more hostile and direct (Parkinson, 2001). The perception of the pedestrian as a vulnerable road user is associated with feelings of understanding and compassion, even if there seem to be cultural differences when using a characterization questionnaire (Andrés \& Gaymard, 2010; Gaymard, Andrés, \& Nzobounsana, 2011). Finally, in this study drivers' reactions appear homogeneous whatever the experience and sex of the driver. Nevertheless, given these results, it would be worth confirming them through the analysis of a greater number of samples.

\section{Acknowledgment}

This study is supported by a grant from La Fondation Sécurité Routière.

\section{References}

Abric, J.-C. (1976). Jeux, conflits et représentations sociales. Thèse de doctorat d'Etat. Aix-en-Provence: Université de Provence.

Abric, J.-C. (Ed.) (1994). Pratiques sociales et représentations. Paris: Presses universitaires de France.

Abric, J.-C. (Ed.) (2003). Méthodes d'étude des représentations sociales. Ramonville Saint-Agne: Erès.

Alhakami, A.S. \& Slovic, P. (1994). A psychological study of the inverse relationship between perceived risk and perceived benefit. Risk Analysis, 14, 1085-1096.

Andrés, S. \& Gaymard, S. (2010). The representation of the pedestrian by young drivers: a theoretical reflexion on the cultural construction of representations. In Actes du Colloque International ITFH «Infrastructures, Technologies and human factors :Multidisciplinary approach of the safety in means of Transportation» (pp. 57-58). Angers: Université d'Angers.

Bauer, M.W. \& Gaskell, G. (1999). Towards a paradigm for research on social representations. Fournal for the Theory of Social Behaviour, 29, 163-186.

Benzecri, J.-P. (1980). L'analyse des données tome 2: L'analyse des correspondances. Paris: Bordas.

Borowsky, A., Shinar, D., \& Oron-Gilad, T. (2010). Age, skill, and hazard perception in driving. Accident Analysis \& Prevention, 42, 1240-1249. 
Breakwell, G.M. (2001). Mental models and social representations of hazards: The significance of identity processes. Journal of Risk Research, 4, 341-351.

Breakwell, G.M. (2007). The psychology of risk. Cambridge, UK: Cambridge University Press.

Chan, E., Pradhan, A.K., Pollatsek, A., Knodler, M.A., \& Fisher, D.L. (2010). Are driving simulators effective tools for evaluating novice drivers' hazard anticipation, speed management, and attention maintenance skills? Transportation Research Part F: Traffic Psychology and Behaviour, 13, 343-353.

Crundall, D., Underwood, G., \& Chapman, P. (1999). Driving experience and the functional field of view. Perception, 28, 1075-1087.

Doise, W. (1985). Les représentations sociales: Définition d'un concept. Connexion, 45, 243-253.

Doise, W., Clemence, A., \& Lorenzi-Cioldi, F. (1992). Représentations sociales et analyses de données. Grenoble: Presses Universitaires de Grenoble.

Durkheim, E. (1898/1967). Représentations individuelles et représentations collectives. Revue de Métaphysique et de morale, Tome VI, republié in Sociologie et philosophie. Paris: Presses universitaires de France.

Evans, T. \& Macdonald, W. (2002). Novice driver situation awareness and hazard perception: An exploratory study. In Road Safety Research, Policing and Education Conference, Adelaide, South Australia, Australia. Vol. 1 (pp. 85-90). Walkerville: Transport SA.

Farr, R. (1984). Les représentations sociales. In S. Moscovici (Ed.), Psychologie sociale (pp. 379-389). Paris: Presses Universitaires de France.

Farr, R. (1987). Social representations: A French tradition of research. fournal for the Theory of Social Behaviour, 17, 343-365.

Finn, P. \& Bragg, B.W.E. (1986). Perception of the risk of an accident by young and older drivers. Accident Analysis and Prevention, 18, 289-298.

Finucane, M.L., Alhakami, A.S., Slovic, P., \& Johnson, S.M. (2000). The affect heuristic in judgements of risk and benefits. Journal of Behavioral Decision Making, 13, 1-17.

Garay-Vega, L., Fisher, D.L., \& Pollatsek, A. (2007). Hazard anticipation of novice and experienced drivers: Empirical evaluation on a driving simulator in daytime and night time conditions. Transportation Research Record, 2009, 1-7.

Gaymard, S. (2003). La négociation interculturelle chez les filles franco-maghrébines: Une étude de représentation sociale. Paris: L'Harmattan.

Gaymard, S. (2007). La représentation de la conduite chez des jeunes conducteurs: Une étude de la conditionnalité routière. Recherche Transports Sécurité, 97, 339-359.

Gaymard, S. (2009). Norms in social representations: Two studies with French young drivers. The European fournal of Psychology Applied to Legal Context, 1, 165-181.

Gaymard, S., Agbotsoka, T., \& Nzobounsana, V. (2009). La représentation des interactions conducteurs/piétons: Une approche des émotions (The representation 
of driver/pedestrian interactions: An approach of emotions). Actes du colloque organisé par l'ADRIPS, Emotions en psychologie sociale (p. 49). Paris: Université Paris Ouest Nanterre La Défense.

Gaymard, S., Allain, P., Osiurak, F., \& Le Gall, D. (2011). The conditions of respect of rules in young and elderly drivers: An exploratory study. The European Journal of Psychology Applied to Legal Context, 3, 11-28.

Gaymard, S., Andrés, S., \& Nzobounsana, V. (2011). La representación social y las emociones de los conductores Franceses y Españoles acerca de los peatones (Social representation and emotions in French and Spanish drivers toward pedestrians). In F. Expósito, M.C. Herrera, G. Buela-Casal, M. Novo, \& F. Fariña (Eds.), Psicología jurídica. Áreas de investigación (pp. 435-442). Santiago de Compostela: Consellería de Presidencia, Xustiza e Administracións Públicas.

Gaymard, S., Boucher, V., Nzobounsana, V., Greffier, F., \& Fournela, F. (2012). La perception des piétons par les conducteurs: corrélations entre les données d'un œil électronique et le verbatim des conducteurs / Drivers' perception of pedestrians: correlations between the data of an electronic eye and drivers' verbatim. Canadian fournal of Behavioural Science / Revue canadienne des sciences du comportement. Advance online publication. http://psycnet.apa.org/ doi/10.1037/a0025789

Groeger, J.A. \& Chapman, P.R. (1996). Judgement of traffic scenes: The role of danger and difficulty. Applied Cognitive Psychology, 10, 349-364.

Hewstone, M. \& Augoustinos, M. (1998). Social attributions and social representations. In U. Flick (Ed.), The psychology of the social (pp. 60-76). Cambridge, UK: Cambridge University Press.

Holland, C. \& Hill, R. (2007). The effect of age, gender and driver status on pedestrians' intentions to cross the road in risky situations. Accident Analysis and Prevention, 39, 224-237.

Joffe, H. (1999). Risk and 'the other'. Cambridge, UK: Cambridge University Press. Joffe, H. (2003). Risk: From perception to social representation. British fournal of Psychology, 42, 55-73.

Joffe, H. \& Lee, L. (2004). Social representation of a food risk: The Hong Kong avian bird flu epidemic. Health Psychology, 9, 517-533.

Jovchelovitch, S. (1996). In defense of representations. fournal for the Theory of Social Behaviour, 26, 121-135.

Khan, F.M., Jawaid, M., Chotani, H., \& Luby, S. (1999). Pedestrian environment and behaviour in Karachi, Pakistan. Accident Analysis and Prevention, 31, 335-339.

Krotosky, S.J. \& Trivedi, M.M. (2007). On color-, infrared-, and multimodal-stereo approaches to pedestrian detection. IEEE Transactions on Intelligent Transportation Systems, 8, 619-629.

Languin, N., Widmer, E., Kellerhals, J., \& Robert, C-N. (2004). Les représentations sociales de la justice pénale: Une trilogie. Déviance et Société, 28 (2), 159-178. 
Maeda, K., Uchiyama, A., Umedu, T., Yamaguchi, H., Yasumoto, K., \& Higashino, T. (2009). Urban pedestrian mobility for mobile wireless network simulation. Ad Hoc Networks, 7, 153-170.

Maycock, G. \& Forsyth, E. (1997). Cohort Study of learner and novice drivers, Part 4: Novice driver accidents in relation to methods of learning to drive, performance in the driving test and self assessed driving ability and behaviour. TRL Report 275. Crowthorne, UK: Transport Road Research Laboratory.

Moscovici, S. (1961/76). La psychanalyse, son image et son public. Paris: Presses Universitaires de France.

Parkinson, B. (2001). Anger on and off the road. British fournal of Psychology, 92, 507-526. Piaget, J. (1977). Mes idées. Paris: Denoël/Gonthier.

Pollatsek, A., Fisher, D., \& Pradhan, A. (2006). Identifying and remedying failures of selective attention in younger drivers. Current Directions in Psychological Science, 15, 255-259.

Roland-Levy, C. (2004). De la psychologie sociale à la psychologie économique en passant par la psychologie politique. Les cahiers psychologie politique, 5. Retrieved from:

http://lodel.irevues.inist.fr/cahierspsychologiepolitique/index.php?id=1302

Sarkar, S. \& Andreas, M. (2004). Drivers' perception of pedestrians' rights and walking environments. Transportation Research Record, 1878, 75-82.

Schmidt, S. \& Färber, B. (2009). Pedestrians at the kerb - Recognising the action intentions of humans. Transportation Research Part F: Traffic Psychology and Behaviour, 12, 300-310.

Scialfa, C.T., Deschênes, M.C., Ference, J., Boone, J., Horswill, M.S., \& Wetton, M. (2011). A hazard perception test for novice drivers. Accident Analysis and Prevention, 43, 204-208.

Thompson, S.J., Fraser, E.J., \& Howarth, C.I. (1985). Driver behaviour in the presence of child and adult pedestrians. Ergonomics, 28, 1469-1474.

Tom, A., Auberlet, J.M., \& Brémond, R. (2008). Approche psychologique de l'activité de traversée de piétons. Implications pour la simulation microscopique du trafic urbain. Recherche Transports Sécurité, 101, 265-279.

Tsoukalas, I. (2006). A method for studying social representations. Quality and Quantity, 40, 959-981.

Tversky, A. \& Kahneman, D. (1974). Judgement under uncertainty: Heuristics and biases. Science, 185, 1124-1131.

Underwood, G., Phelps, N., Wright, C., Loon, E.V., \& Galpin A. (2005). Eye fixation scanpaths of younger and older drivers in a hazard perception task. Ophthalmic Physiological Optic, 25, 346-356.

Viaud, J. (2005). Représentations du régime de Vichy ou «se souvenir de ne pas oublier». Temporalités, 3, 15-40.

Vergès, P. (2001). L'analyse des représentations sociales par questionnaires. Revue française de sociologie, 42, 537-561. 
Wagner, W. (1996). Queries about social representation and construction. Journal for the Theory of Social Behaviour, 26, 95-120.

Widmer, E., Languin, N., Pattaroni, L., Kellerhals, J., \& Robert, C.N. (2004). Du sentiment d'insécurité aux representations de la délinquance. Déviance et Société, 28 (2), 141-157.

Zajonc, R. B. (1980). Feeling and thinking: Preferences need no inferences. American Psychologist, 35, 151-175.

\section{Appendix: Little stories to complete}

1. While you are driving in town, a pedestrian steps out inconsiderately. You let him or her cross and receive a sign of thanks...

2. You are at a red light. A bike overtakes you on the right and goes through the red light. You wait, the light turns green and as you advance, a pedestrian steps out onto the road...

3. You are driving in town, on the sidewalk you see a pedestrian who manifestly seems impatient to cross...

4. While you are driving in town, a pedestrian steps out inconsiderately forcing you to stop, he passes without looking at you...

5. You are driving in town, on the sidewalk, a man in a suit, obviously a businessman, is going to cross outside the pedestrian crossing...

6. It is raining, you are driving in town when someone loaded with shopping wants to step out onto the road...

7. You are driving in town, a group of pedestrians step out onto the road although they shouldn't cross (green light for the driver)...

8. You are driving in the country and in the distance you notice a pedestrian walking on the side of the road...

9. In town while you are driving at normal speed, a person crosses slowly on purpose...

10. In the country during nighttime ( 2 a.m.), you are driving when, in your headlights, you make out a human form...

11. You are driving in town, an elderly person forces you to stop, putting up a hand in front of your car... 